\title{
Collaborative learning: implementation of JigSaw technique in a Google environment
}

Orcos, Lara ${ }^{a, c, 1}$; Arias, Rosario ${ }^{\text {; }}$ Aris, Nuria ${ }^{\text {a,1 }}$ and Magreñán, Ángel Alberto ${ }^{\text {b, } 1}$

${ }^{a}$ Department of Education, Universidad Internacional de La Rioja (UNIR), Gran Vía Rey

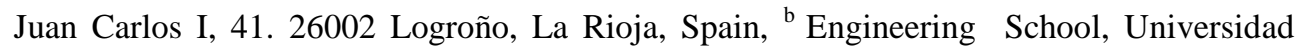
Internacional de La Rioja (UNIR), Gran Vía Rey Juan Carlos I, 41. 26002 Logroño, La Rioja, Spain, ${ }^{\mathrm{c}}$ Department of Education, Universidad Nacional de Educación a Distancia (UNED), C/ Bravo Murillo, 38 3 ${ }^{\mathrm{a}}$, 28015, Madrid, Spain. ${ }^{1}$ This work is partially supported by Ministerio de Ciencia y Tecnología MTM2014-52016-C02-1-P, by UNIR Research (http://research.unir.net), Universidad Internacional de La Rioja (UNIR, http://www.unir.net), under the Research Support Strategy 3 [2015-2017], Research Group: MOdelación Matemática Aplicada a la Ingeniería (MOMAIN), by the Grant SENECA 19374/PI/14 .

\begin{abstract}
The main purpose of this research is checking the effectiveness of some online collaborative learning techniques through the development and implementation of a Google-based environment which will let us develop the collaborative technique known as Jigsaw. The research has been carried out on maths students of a school in the Principality of Asturias. 28 students from different school years and classes took part in the research and several teachers at the school also participated in it. We have used a quasiexperimental design with pre-test and post-test measures as well as an equivalent control group. We have also carried out a detailed study of the requirements needed to extract information about the problems of the implementation of online collaborative activities in the classroom and about the creation of such activities focused on the use of classroom blogs and interactive animations. The results of the analysis show that a methodology such as this exerts a positive influence not only on the students' motivation but also on their academic achievements' the aims of the work, the main results obtained, and the conclusions drawn.
\end{abstract}

Keywords: Collaborative learning, Jigsaw Technique, cloud computingbased learning, mathematics, Google environment, educational technology. 


\section{Introduction}

The main objective of this research is to study the effectiveness of using a previously designed online environment for learning maths throughout a collaborative methodology. It is studied whether the use of this environment influences positively on student motivation for the mathematics content, if teachers consider it an effective and facilitating learning experience giving special attention to students with learning difficulties and Special Educational Needs.

The work developed describes a learning experience using the active methodology based on the Jigsaw Technique ( Aronson \& Patnoe, 1997) in which several competences are aborded in an integrated way throughout several activities to develop mathematical contents related with integers and powers. Students are aged between 12 and 16 years old and were divided in two groups, control and experimental. While the control group has been working in a traditional way, the experimental one worked in an online environment and through a collaborative methodology. As pretest measure the mark obtained in the initial test on students when starting the course in the subject of mathematics has been used. Most students participating in the experience belong to the first course of Secondary Education and it is the first year they are at school and post-test measures are the results of a survey conducted by Google Form prepared by the teacher, questions have 4 possible answers, of which only one is correct. It needs to be noted that all students had previously worked in preceding years with the issue of powers, although some contents, such as the properties of the operations of powers, were new for first year pupils.

Previously to the intervention phase, a requirements study using a survey was carried out to determine the knowledge and experience of students in the use of ICT and the technological means available outside the center, the availability of teachers to participate in the educational intervention, their opinions and experience in the collaborative teachinglearning processes, and their motivation to use ICT in the classroom, and a study of the availability of resources, number of computers, compatible schedules free classrooms, internet center characteristics, etc.

\section{Background}

Recent studies (Vandecandelaere, M., Speybroeck, S., Van Laar, G., De Farine, B., \& Van Damme, J., 2012) show that there is a close relationship between the use of learning platforms and students attitude to mathematics and that the results of the students improved significantly. There have been numerous theoretical studies on methodologies that lead to a definition of collaborative learning, (Guitert, M., \& Pérez-Mateo, M., 2013) but there are less pilot projects in the field of mathematics, intending this research to approach the reality 
of students in the "Principado de Asturias" and experimentally test whether JigSaw technique implemented in Google virtual environment and methodology of direct intervention in the classroom corroborates the theoretical predictions for collaborative environments.

The fact of working in collaborative groups is an essential ingredient in all teaching and learning activities. We can say that all projects using innovative methods or techniques incorporate this way of working as an experience in which the learner develops as a person. The so-called learning theory for the digital age, Connectivism, promoted by George Siemens and Stephen Downes (2015) attempts to explain the complex digital learning in a rapidly changing social world.

Methods or techniques of collaborative learning have been described almost entirely by authors such as Slaving (Slaving, RE, \& Johnson, RT, 1999) and Shepherd (1990). Jigsaw (Aronson, Stephan, Sikes, Blarney, \& Snap, 1978) is a type of collaborative technique in which students are divided in heterogeneous groups each of them consisting of 6 members. Teacher divides the lesson into 6 parts, each of them unique and essential in order to understand the lesson. Each student work one part and them all of them need to be placed together so as to understand the full chart. In this case the evaluation in individual for each student based on an exam of the full content.

There is a variation of this technique, Jigsaw II, in which students work in teams of 4-5 members. All students have to read the whole activity but each of them has a subtheme assigned in which the students needs to be an expert. Debates are carried out between the experts of each subtheme and then, each student returns to the original group to explain it to the mates. The evaluation is in groups based on the punctuations obtained by each group member in the individual exam about the full content.

Aronson (1978) found that the Jigsaw technique or puzzle is particularly effective in the most marginalized students, but generally the advantages that this technique can provide are (Fernández, MT, Morales, FX, \& Marti, J., 2011): 1) Generates an intense interaction among students, since it requires them to be heard, 2) Positive attitudes toward the center and peers are created, 3) Self-esteem increases significantly, 4) Reduces hostilities, tensions and prejudices, 5) Improves academic performance, 6) Reduces their competitiveness, 7) Helps them see their peers as sources of learning, 8) Promotes the ability to empathize

The incorporation of ICTs to this technique requires its adaptation in order to ensure an effective implementation using the collaborative tools provided by educational platforms. The combination of collaborative techniques and online environments improve the teaching and learning processes if the following requirements are fulfilled: 1) They have to transform interpsicological processes into intrapsicological ones, from both teacher and student perspective, 2) They need to be built in a quality environment based on community 
working for the teaching and learning processes, 3) They have to develop key ecompetences for both teaching and learning, taking the previous points into account.

Improvement projects at university level, in response to the demands of the European Higher Education Space include experiences in virtual environments applying collaborative techniques considered motivating and enriching. In education Primary and Secondary education these experiences had been limited to geographically isolated centers in which collaboration between centers allowed to overcome this isolation. With the New Law of Education in Spain, it is necessary that these experiences are incorporated into the classroom as one of the methodological varieties for the competences treatment, so that, it is necessary to investigate the variables that influence in the development of collaborative networking activities with students in secondary education also with the technological resources available at the centers whose characteristics differ essentially from those centers and students of higher education. It is necessary to find easily accessible virtual environments from classrooms and outside them, and which do not require prior knowledge and excessive experience neither for teachers, who have to configure the environment and has to provide and organize the activities on it, nor for students who have to handle new tools and adapt to new methodologies.

\section{Objectives}

\subsection{Research hypothesis}

The literature review and the background checks detect a problem to which this paper tries to answer describing a virtual environment that allows us to implement an efficient collaborative technique to secondary school students and to allow the development of specific mathematical content, while the following curriculum competences are working.

"The addition of teaching and learning techniques based on collaborative online environments to the classroom significantly improve the results of secondary students and their motivation."

"Google environment in the Network with the tools it offers, provides the effective implementation of the collaborative technique JigSaw".

\subsection{General objective}

To improve students' performance and motivation by incorporating collaborative techniques in the classroom using online tools that provide the necessary resources in order to create a Google-based environment that enables the implementation of JigSaw technique.

\subsection{Specific objectives}

- To implement the JigSaw technique in Google with the tools described above. 
- To increase the students' motivation, especially in mathematics, with the incorporation of students from different courses in the groups and to analyze the evolution of the students in all aspects in the development of the experience.

- To improve the results in students with special education needs and to integrate them with the rest of their mates.

\section{Methodology}

\subsection{Research Design}

Frist of all, students' previous knowledge and motivation, Teachers' expectative, experiences and opinion and Specific school characteristics, available infrastructure were analyzed in order to carry out the requirements study:

A quantitative quasi-experimental methodology is used due to the presence of strange and uncontrollable variables and a causal link between the before and after of the intervention process with the virtual environment without any randomness in the allocation of control subjects is intended to be stablished. Data obtained are the numerical results of observable realities dependent of use or not of the collaborative online environment, independent variable, we can manipulate.

Conducting a pre-test (before surgery) and post-test (post-intervention) by the experimental and control groups allows comparing the academic performance over the contents studied. Conducting satisfaction surveys and direct observation throughout the entire process, make possible to analyze the students' motivation and satisfaction with the participation in this type of experience.

\subsection{Population and sample}

Population: Formed by students of Secondary Education, of the Public Center CPEB Carlos Bousoño in course of Mathematics in all its forms.

Sample: The sample consists of 28 students aged between 12 and 16 years, 18 students are in first grade $\mathrm{y}$ the remaining 10 belong to other courses. Two of the students who participated are students with Special Educational Needs, SEN, so the participation and collaboration of Therapeutic Pedagogy teacher has been necessary.

\subsection{Variables studied}

As mentioned above, the independent variable has been the use or not of a collaborative online environment and the dependent variables are defined in terms of competences acquired and they are: digital competence, sense of initiative and entrepreneurship, specific 
contents of the first course of secondary education acquisitions and mathematic competence.

\subsection{Instruments}

The techniques used to carry out the experiment were participant direct observation, structured and group interview using online forums and computerized questionnaires to check the contents acquisition. The instruments used were anecdotal records, control lists and questionnaires.

For this investigation, the tools given by Google, to which the access is easy throughout the creation e-mail account in Gmail, used are: Google Drive, Google Groups and Blogger due to the fact that they are very easy to use, the possibility the access from different devices and the flexibility they contribute to the using of some applications such as calculators or graphs that can have integrating problems when using more conventional environments.

\subsection{Jigsaw Technique implementation}

In the development of the Jigsaw Technique using experts groups the steps are: full group activity introduction, Base groups creation, experts' groups creation, return to the original base group, group work, general presentation, individual evaluation.

The proposed activities included the selection and analysis of videos, animations and Geogebra simulations of integers and powers, the presentation of a summary of theoretical aspects of powers and their history using Google Presentations and the elaboration of a compendium of theoretical and practical activities of the whole contents related with integers and powers taking into account the students with special needs.

\section{Results}

\subsection{Assessment survey about the using of an online environment and collaborative experience.}

The $94 \%$ of the students considered they have learn so much about powers using this methodology and the $100 \%$ found the experience highly motivating. The $83,3 \%$ recognized that the most positive fact of the experience was collaborative learning. The activity that had less positive influence in students was the use of forums.

The use of the online environment outside the classroom has had a good reception among the students and $76,5 \%$ recognized using them at home. The $86 \%$ said they would like to continue using this type of methodology in order to learn in all subjects. 


\subsection{Difference between the experimental and control groups in terms of acquiring specific knowledge.}

The results of the pretest and postest can be seen in Figure 1 which shows that a significant difference between the means of the pretest in both groups is not appreciated as expected because the selection of students is heterogeneous, although it is slightly higher in the control group.

Regarding the means achieved in the postest we see that in the experimental group is significantly higher, demonstrating the effectiveness of the methodology applied. Evolution is good in both groups but the difference in the experimental group is higher.
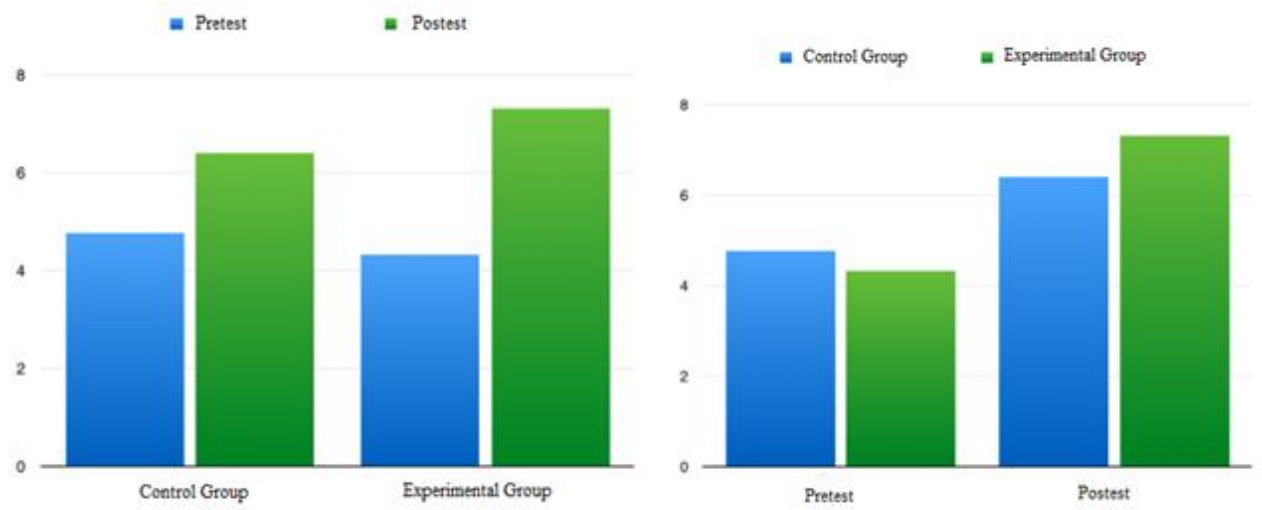

Figure 1: Left: Difference between means in the experimental and control groups. Source: Own Elaboration. Right: Difference between average punctuation in the pretest and postest. Source: Own Elaboration

To evaluate the grade of learning achieved by the students (Gil, Perez, Suero, Solano \& Pardo, 2010) the normalized average gain in each group $(G)$ is calculated. The parameter is higher for the experimental group $(G=0.53)$ than for the control one $(G=0.31)$.

\subsection{Global Students Evaluation}

For the global students evaluation the level of the mentioned indicators achievement has been taken into account. In general, the participation in forums has been low which is understandable considering that they are working in the same room. Blog commentaries has been satisfactory indicating that the student were highly motivating in checking their mates' problems.

The most significant difference has taken place in the global exam being the results in the experimental group higher than in the control one. Form the results, it is concluded that a motivation strategy for the using of forums is necessary. 


\section{Conclusions}

This study has been carried out in order to find an effective way of using a free online environment to implement a collaborative methodology to enhance both the motivation and the academic results of the students. The conclusions obtained are:

- The Jigsaw Technique is easy to integrate in online environments with the characteristics of Goggle environment and stimulate the development of the teaching and learning activities. However, the use of these type of methodologies requires the permanent teacher formation which is needed to be facilitated by the public administrations.

- The use of collaborative methodologies favours both the motivation and the academic results of students but a content selection is needed due to the impossibility to deal with all of them in an online environment.

- Virtual environments are an alternative to the limitations of conventional platforms.

- The teachers and students experiences in the using of these methodologies based on online environments is going to increase and difficulties will decrease as a consequence.

- The use of this type of methodologies benefits the academic results in students with special needs

\section{References}

Aronson E., (1978) The Jigsaw Classroom, Sage Publications, Beverly Hills, California.

Aronson, E., \& Patnoe, S. (1997). The jigsaw classroom: Building cooperation in the classroom (2nd ed.). New York: Addison Wesley Longman.

Downes Stephen \& Siemens George (1995-2016) Knowledge, Learning, Community. Recovered (10-10-2015) de http://www.downes.ca.

Gil, J., Pérez, A. L., Suero, M. I., Solano, F., \& Pardo, P. J. (2010). Evaluation of the effectiveness of a method of active learning based on Reigeluth and Stein's Elaboration Theory. International Journal of Engineering Education, 26(3), 628-641.

Guitert, M., \& Pérez-Mateo, M. (2013). La colaboración en la red: hacia una definición de aprendizaje colaborativo en entornos virtuales. Education in the Knowledge Society (EKS), 14(1), 10-31.

Martínez-Fernández, M. T., Molina-Morales, F. X., \& Traver-Martí, J (2011). Formación de competencias y resultados de aprendizaje a través de la Técnica Puzzle de Aronson: una experiencia universitaria para la mejora educativa.JAC-11, Jornada sobre Aprendizaje Cooperativo SPIEU, USE-UJI Castellón.

Slavin, R. E., \& Johnson, R. T. (1999). Aprendizaje cooperativo: teoría, investigación y práctica. Buenos Aires: Aique. (01999. la ed. trad. Miguel Wald.

Vandecandelaere, M., Speybroeck, S., Vanlaar, G., De Fraine, B., \& Van Damme, J. (2012).

Learning environment and students' mathematics attitude. Studies in Educational Evaluation, http://doi.org/10.1016/j.stueduc.2012.09.001. 